\title{
COVID-19 Pandemic, a War to be Won: Understanding its Economic Implications for Africa
}

\author{
John E. Ataguba ${ }^{1,2}$ \\ Published online: 5 April 2020 \\ C) Springer Nature Switzerland AG 2020
}

\section{Introduction}

The emergence of coronavirus disease (COVID-19) on the global public health scene has led to growing concerns and uncertainties. It has intensified my curiosity about the likely implications of the COVID-19 pandemic in Africa from the perspective of an economist. Africa bears a disproportionate burden of poverty and disease [1], which could be exacerbated by the COVID-19 pandemic. Although the situation is changing rapidly, the initial emphasis was on the clinical and epidemiology aspects of COVID-19, including actions to avoid transmission and infection [2]. Fundamentally, the COVID-19 pandemic increased awareness that a disease does not have a nationality and that we are all connected as one 'global nation'. The fact that coronavirus does not respect national boundaries is really at the core of the global response and solidarity. Recently, for example, the World Bank increased its response and its commitment to assist many countries and, together with the International Monetary Fund, have called on all official bilateral creditors to suspend debt payments from the International Development Association countries requesting forbearance [3]. The fact is that many developed countries are substantially financing COVID-19-related activities in their own countries, which may leave little room for providing relief funds to developing countries. This further blurs the outlook in the current COVID-19 pandemic for most countries in Africa that rely on developed countries for official development assistance.

John E. Ataguba

John.Ataguba@uct.ac.za

1 Health Economics Unit, School of Public Health and Family Medicine, Faculty of Health Sciences, University of Cape Town, Anzio Road, Observatory, Cape Town 7925, South Africa

2 Partnership for Economic Policy, Duduville Campus, Kasarani, Nairobi, Kenya
Until recently, analyses of the economic implications of the COVID-19 pandemic in public media and academic writing have focused mainly on global and macroeconomic impacts, which, as I argue, is only one part of the bigger picture of economic impact. This is especially the case in Africa, with its high disease burden, poorly developed infrastructure and safety nets and weak health systems [4-6]. For instance, the first comprehensive report on COVID-19 from the Brookings Institution [7] modelled the implications of the COVID-19 pandemic on macroeconomic outcomes and financial markets. That report used seven scenarios with global hybrid dynamic stochastic general equilibrium and computable general equilibrium models. Although the COVID-19 outbreak is still unfolding, with South Africa recording the highest number of confirmed cases (1462) in Africa as at 2 April 2020 [8], the preliminary analysis in that report [7] showed that the containment of the COVID-19 pandemic would yet have an impact on global economies in the short term. Interestingly, that report concluded that significant costs associated with the COVID-19 pandemic "might be avoided by greater investment in public health systems in all economies but particularly in less developed economies where health care systems are less developed and population density is high" (p. 1).

Indeed, the finding regarding increased investment in public health systems is not surprising, given what we have learnt in Africa from the Ebola epidemic [9, 10]. Importantly, health systems must be prepared and resilient to address outbreaks such as the COVID-19 pandemic. Health systems resilience is about being aware, diverse, self-regulating, integrated and adaptive [9]. The integrated aspect is worth highlighting briefly. Here, the role of different actors, including individuals, communities and organisations, in following basic principles and protocols such as staying or working from home, self-isolating suspected cases, social distancing, practising good hygiene, avoiding large gatherings, etc., would significantly reduce infections and the spread of the disease. 
That said, let me come to an issue that is crucial to understanding the economic implications of the COVID19 pandemic in the African setting. I will note the two primary drivers of economic costs among different economic agents (e.g. individuals, households, firms, health facilities, governments, etc.) that are not mutually exclusive: (1) uncertainty or panic and (2) actual or suspected cases and deaths. Here, panic relates to how agents perceive COVID19 and the fear and anxiety that accompany the outbreak, which are not entirely evidence based. Sometimes, actual or suspected cases and deaths increase uncertainty and panic, which also affect how the different agents behave. Whether it is uncertainty or panic or actual or suspected cases and deaths that drive the economic cost, I want to distinguish two aspects that must be looked at when we discuss the economic burden or cost of the COVID-19 pandemic, especially in Africa: microeconomic and macroeconomic impacts.

So, what are the accompanying micro- and macroeconomic costs associated with the COVID-19 pandemic in Africa? Unfortunately, the answer to this question is not straightforward, given, inter alia, the emergent nature of the pandemic, the different levels of preparedness, epidemiologic patterns, and the distribution of the social determinants of health in Africa. However, I want to draw on what we know from other parts of the world, especially China, to provide an essential conceptual understanding of how we can assess these impacts and what they may likely be in Africa. As an economist, it is crucial to highlight that the costs associated with the COVID-19 pandemic are not just about direct financial outlays but include the opportunity cost. For example, the opportunity cost of an individual's time not spent in productive work activity due to COVID-19 is the productivity cost to an employer [11].

Although scientists caution that it is too early to estimate accurate case fatality rates for COVID-19 [12, 13], evidence from China indicates that it increases with comorbidities and age, with exceptionally high rates $(>14 \%)$ among adults aged at least 80 years $[14,15]$. Looking at the population pyramid in Africa, less than $0.5 \%$ of the African population is aged at least 80 years, with about $89 \%$ aged less than 50 years (Fig. 1). The crude case fatality rate for COVID-19 was estimated at less than $0.4 \%$ for people aged less than 50 years in China. In Africa, the population is relatively young but does bear a high mortality burden from pneumonia and tuberculosis, which are implicated in about $12 \%$ of deaths on the African continent (Fig. 1). Because COVID19 complication may manifest with more severe symptoms than pneumonia, this will likely increase the mortality rate for all age groups, particularly among the elderly, the immunocompromised and those with comorbidities [14]. In Africa, the capacity of the weak health system could aggravate the situation, as seen during the Ebola epidemic [10].

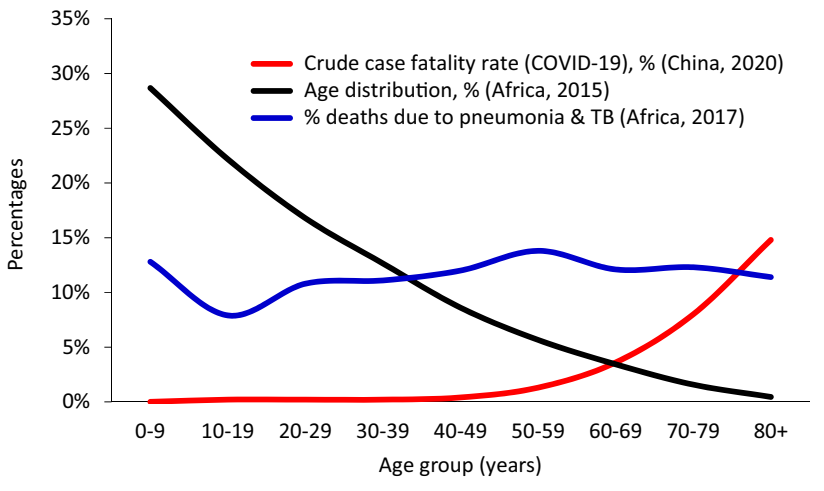

Fig. 1 COVID-19 case fatality rate [14], age distribution [16] and pneumonia/tuberculosis (TB) deaths [17]

\section{What are the Microeconomic Costs Associated with the COVID-19 Pandemic?}

The microeconomic costs of the COVID-19 pandemic relate to those borne by individuals/households, firms and other establishments like schools, hospitals, clinics, health centres, health facilities, health workers and the government. This includes the burden of morbidity and mortality. With the COVID-19 pandemic, families may bear costs for diagnosis and treatment where, for example, they are not covered by the government or health insurance schemes. Even where these costs are covered, households may still incur copayments, transport costs and other related expenses, including the indirect costs of care. Out-of-pocket health spending remains high in many African countries and could be as high as $>70 \%$ of current health expenditures as in Cameroon, Comoros, Equatorial Guinea, Guinea Bissau and Nigeria [18]. The COVID-19 pandemic could exacerbate the burden of outof-pocket health spending on households in Africa and dampen financial protection for health.

Any restriction on or removal of the ability to work and earn a living, especially for informal workers who are predominantly women and account for about $89 \%$ of all employment in sub-Saharan Africa, will put a strain on families [19]. The precarious nature of informal work, as evidenced by the absence of a contract or income protection, means that their sources of livelihood may be impacted significantly by the COVID-19 pandemic, especially when countries experience lockdown. For example, South Africa has one of the lowest shares of informal workers, accounting for about one-third of all workers [20], and their contribution is estimated at $\sim 10 \%$ of the country's gross domestic product (GDP) [21]. While there may not be a full impact on informal work, the $10 \%$ of South Africa's GDP is higher than the share of total health 
expenditure in the country's GDP $(\sim 8 \%)$ [22]. The impact on other African countries with a relatively high informal sector will be more significant.

Some private establishments have provided infrastructure, including the commitment of funds to assist the government in addressing the COVID-19 pandemic. Many firms and establishments will incur productivity losses from any closure of businesses and from giving employees leave to stay at home to avoid any possible spread of the virus. They may also incur costs related to keeping their work environments disinfected. Schools may close. Shops, including informal grocery stores, bars and restaurants, may also close or face a significant decline in demand. In some countries, mining and agricultural activities will be affected significantly. The postponement or cancellation of many activities such as sports events, conferences, symposiums and workshops will substantially impact on conference organising companies and individuals who may have pre-booked travel and accommodation. Travel companies, especially airlines, may have fewer customers, cancel flights and/or face an increased marginal cost necessary to keep the environment disinfected. Hotels and other hospitality and tourism businesses will have a significantly reduced number of clients. Unfortunately, the associated 'microeconomic' costs in Africa are difficult to estimate accurately at this moment as the COVID-19 outbreak continues to unfold and costs will depend on the extent of the uncertainty/panic and actual/ suspected cases and deaths. However, productivity losses associated with strike actions indicate likely impacts. For example, although this is narrow, the 2014 platinum mining strike in South Africa led to a reduction of $0.72-0.78 \%$ in the country's real GDP [23]. It is undeniable that the total cost of any temporary closure or staff leave granted by firms and other private establishments will exceed that reported for the platinum mining strike, especially in many African countries where informal work dominates.

In many African countries, government spending on health is relatively small [18]. Substantial additional costs are associated with the COVID-19 outbreak for governments. A decline in economic activity may significantly impact on the country's revenue generation, especially tax revenue (both direct and indirect taxes). During this period, public health spending is also expected to increase to manage and treat health service users and contain the spread of the virus. Furthermore, the cost of quarantining returnees and other cases needs to be borne by governments. Generally, governments will incur costs related to building, equipping and maintaining infrastructure to manage, treat and contain the COVID-19 pandemic. Governments may also be faced with the need to provide income relief and support to households affected by temporary workplace closures, for example. The magnitude of public funds will depend, inter alia, on the future infection rate, the severity of infections and the ability of many countries in Africa to reduce numbers of new infections.

Other health-related opportunity costs emanate from the significant emphasis that countries place on tackling the COVID-19 pandemic. For example, in some countries in Africa, even with limited public funds, a 'crowding-out' effect may occur as increased public health spending to tackle the COVID-19 pandemic may reduce funding for other critical public health priorities such as communicable, nutritional and infectious diseases. This could result in reduced access to certain health services, which may increase the burden of disease. Self-isolation and lockdown may also affect mental and physical health significantly because social isolation is adversely related to health (mental and physical) [24]. Households locked down in unfavourable housing conditions (e.g. over crowded with poor ventilation), which characterise many rural and informal urban settings and slums in Africa, may face adverse health outcomes.

\section{What About the Macroeconomic Burden?}

The macroeconomic impact of the COVID-19 pandemic is the most talked-about economic effect in popular media. In summary, macroeconomic impacts result from a combination of 'demand' and 'supply' shocks in the economy. These impacts can be summed up by looking at, for instance, the effects of the pandemic on macroeconomic aggregates such as the country's GDP, unemployment rate and inflation rate.

For example, commodity scarcity created by a decline in productivity (or reduction in imports from countries affected by the COVID-19 pandemic) could fuel a rise in general price levels (i.e. inflation). Also, when export-oriented firms or enterprises are unable to export goods, the demand for exports and export income will decline, which may be accompanied by the downsizing of production units and/or the laying-off of workers. In Nigeria, for instance, the falling global price of oil in the face of the COVID-19 pandemic has forced the country to devalue the Naira. Importantly, the impact of several activities on GDP growth will indicate the implication of the COVID-19 pandemic on aggregate economic activities in countries. In South Africa, for instance, the 2020 growth forecast was revised downward from 0.7 to $0.4 \%$ following the COVID-19 outbreak [25]. The COVID-19 pandemic has also affected the stock and financial markets.

\section{Conclusion}

From studies on socioeconomic inequalities in health, we know that poor and vulnerable populations may bear a greater burden of COVID-19 in the long term [26, 27]. 
However, the full economic impact of COVID-19 on the economies of countries in Africa cannot be ascertained at the moment as the situation unfolds. Nevertheless, it is essential to note that, in addition to deaths and significant morbidities from the COVID-19 pandemic, there will be a substantial cost to the economy, which requires drastic steps and actions, backed by a strong will and desire from the government and its people. Several measures are being implemented by African countries, including school closures, travel bans, limits on large gatherings, increased testing and country lockdown. Containing the spread and reducing the economic impact of the COVID-19 pandemic will require a multipronged approach and cooperation from all parties, including substantial reductions in uncertainty levels, panic levels and disease transmission, the primary channels through which the economic impact manifests. Importantly, just like in times of war, when a country's spending on defence increases significantly, countries in Africa must view the COVID-19 pandemic as a 'war' to be won and be prepared to increase public health spending significantly.

\section{Compliance with Ethical Standards}

Funding John E. Ataguba is supported by the South African Research Chairs Initiative of the Department of Science and Technology and National Research Foundation.

Conflict of interest John E. Atagub has no conflicts of interest that are directly relevant to the content of this editorial.

\section{References}

1. Castaneda Aguilar RAL, Christoph Prydz, Espen B. Soler Lopez, Jorge $\mathrm{Wu}$, Ruoxuan Zhao, Qinghua. Estimating global poverty in stata: the povcalnet command. Estimating Global Poverty in Stata. Washington DC: World Bank.

2. Gilbert M, Pullano G, Pinotti F, Valdano E, Poletto C, Boëlle $\mathrm{P}-\mathrm{Y}$, et al. Preparedness and vulnerability of African countries against importations of COVID-19: a modelling study. Lancet. 2020;395(10227):871-7.

3. World Bank. Joint statement from the World Bank Group and the International Monetary Fund regarding a call to action on the debt of IDA countries. The World Bank Group, Washington DC. 2020. https://www.worldbank.org/en/news/statement/2020/03/25/ joint-statement-from-the-world-bank-group-and-the-internatio nal-monetary-fund-regarding-a-call-to-action-on-the-debt-ofida-countries. Accessed 27 Mar 2020.

4. O'Hare B. Weak health systems and Ebola. Lancet Global Health. 2015;3(2):e71-e7272.

5. Gouda HN, Charlson F, Sorsdahl K, Ahmadzada S, Ferrari AJ, Erskine $\mathrm{H}$, et al. Burden of non-communicable diseases in sub-Saharan Africa, 1990-2017: results from the Global Burden of Disease Study 2017. Lancet Global Health. 2019;7(10):e1375-e13871387.

6. McIntyre D, Obse AG, Barasa EW, Ataguba JE. Challenges in financing universal health coverage in sub-Saharan Africa. Oxford Res Encyclop Econ Financ. 2018;2018(5):1-80.
7. McKibbin W, Fernando R. The global macroeconomic impacts of COVID-19: seven scenarios. Washington DC: The Brookings Institution; 2020.

8. Mamoon N, Rasskin G. COVID-19. Navid Mamoon and Gabriel Rasskin, Pittsburg. 2020. https://www.covidvisualizer.com/. Accessed 3 Apr 2020.

9. Kruk ME, Myers M, Varpilah ST, Dahn BTJTL. What is a resilient health system? Lessons from Ebola. Lancet. 2015;385(9980):1910-2.

10. Kieny M-P, Evans DB, Schmets G, Kadandale S. Health-system resilience: reflections on the Ebola crisis in western Africa. Bull World Health Organ. 2014;92(12):850.

11. Culyer AJ. The dictionary of health economics. Cheltenham and Northampton: Edward Elgar; 2005.

12. Lipsitch M, Swerdlow DL, Finelli L. Defining the epidemiology of Covid-19—studies needed. N Engl J Med. 2020;382:1194-6.

13. Battegay M, Kuehl R, Tschudin-Sutter S, Hirsch HH, Widmer AF. Neher RA (2020) 2019-novel Coronavirus (2019-nCoV): estimating the case fatality rate-a word of caution. Swiss Med Wkly. 2020;150:0506.

14. Zhang Y. Analysis of epidemiological characteristics of new coronavirus pneumonia. Chin J Epidemiol. 2020;41(2):1-7.

15. $\mathrm{Wu} \mathrm{Z,} \mathrm{McGoogan} \mathrm{JM.} \mathrm{Characteristics} \mathrm{of} \mathrm{and} \mathrm{important} \mathrm{lessons}$ from the coronavirus disease 2019 (COVID-19) outbreak in China: summary of a report of 72314 cases from the Chinese Center for Disease Control and Prevention. JAMA. 2020 (Epub ahead of print).

16. Economic Commission for Africa. The demographic profile of African countries. Addis Ababa: Economic Commission for Africa; 2016.

17. IHME. GBD Compare I Viz Hub. Institute for Health Metrics and Evaluation (IHME), Washington. 2020. https://vizhub.healthdata .org/gbd-compare/. Accessed 27 Mar 2020.

18. World Health Organization. Global health expenditure database. Geneva: World Health Organization, 2020. https://apps.who.int/ nha/database/ViewData/Indicators/en. Accessed 14 Mar 2020.

19. Bonnet F, Vanek J, Chen M. Women and men in the informal economy: a statistical picture. Manchester: Women in Informal Employment: Globalizing and Organizing (WIEGO); 2019.

20. Budlender D. Statistics on informal employment in South Africa. Manchester: Women in Informal Employment: Globalizing and Organizing (WIEGO); 2011

21. Davies R, Thurlow J. Formal-informal economy linkages and unemployment in South Africa. Pretoria: Human Sciences Research Council (HSRC); 2009.

22. Global Health Expenditure Database [online database]. Geneva: World Health Organization, 2019. https://apps.who.int/nha/datab ase/ViewData/Indicators/en. Accessed 27 Mar 2020.

23. Bohlmann HR, Van Heerden JH, Dixon P, Rimmer M. The impact of the 2014 platinum mining strike in South Africa: An economywide analysis. J Econ Model. 2015;51:403-11.

24. Leigh-Hunt N, Bagguley D, Bash K, Turner V, Turnbull S, Valtorta $\mathrm{N}$, et al. An overview of systematic reviews on the public health consequences of social isolation and loneliness. Public Health. 2017;152:157-71.

25. Donnelly L. Coronavirus forces Moody's to cut SA growth forecast again. BusinessDay. 2020;2020:6.

26. Ataguba JE, Akazili J, McIntyre D. Socioeconomic-related health inequality in South Africa: evidence from General Household Surveys. Int J Equity Health. 2011;10(1):48.

27. Ichoku HE, Mooney G, Ataguba JE. Africanizing the social determinants of health: embedded structural inequalities and current health outcomes in Sub-Saharan Africa. Int J Health Serv. 2013;43(4):745-59. 